\title{
A review on osteoporosis in men
}

\author{
Ioannis P. Stathopoulos, ${ }^{1,2}$ Efstathios G. Ballas, ${ }^{3}$ Kalliopi Lampropoulou-Adamidou, ${ }^{1,2}$ \\ George Trovas ${ }^{1}$
}

${ }^{1}$ Laboratory for the Research of the Musculoskeletal System "Theodoros Garofalidis", ${ }^{2}$ Third Orthopaedic Department, University of Athens, KAT Hospital, Athens, Greece, ${ }^{3}$ First Orthopaedic Department, University of Athens, "Attikon" Hospital, Athens, Greece

\section{INTRODUCTION}

While osteoporosis has been traditionally considered as a disease of aging women, it is becoming an increasingly important male health problem, with one in three fragility fractures after the age of 50 years occurring in men. ${ }^{1}$ These fractures are associated with consequences that in many cases are more severe in men than in women. Increased mortality and major morbidity, including loss of independence, reduced function and mobility, pain, kyphosis and respiratory compromise, are some of them. ${ }^{2}$ However, a great proportion of men with osteoporosis are not diagnosed and do not receive any treatment. This phenomenon is observed even in men who have sustained an osteoporotic fracture, with only about $10 \%$ under anti-osteoporotic treatment. It is also worrisome that studies that have highlighted the underdiagnosis/ undertreatment problem come from countries with advanced health utilities. ${ }^{3,4}$ This review of the literature

Key words: Male osteoporosis, Men, Osteoporosis, Primary osteoporosis

Address for correspondence:

Ioannis P. Stathopoulos, MD, MSc, Laboratory for the Research of Musculoskeletal System "Theodoros Garofalidis", University of Athens, KAT Hospital, 10 Athinas Str., Kifissia, 14561, Athens, Greece, Tel.: +30 2108018123, Fax: +30 2108018122, E-mail: ipstathopoulos@gmail.com Received 17-09-2014, Accepted 30-09-2014 summarizes the latest knowledge about osteoporosis in men, focusing on epidemiology, pathogenesis of primary male osteoporosis, diagnosis and treatment.

\section{DEFINING “OSTEOPOROSIS" IN MEN}

In 1994, the World Health Organization (WHO) defined osteoporosis, osteopenia and normal bone status based on the T-score of dual-energy X-ray absorptiometry (DXA). Diagnosis of osteoporosis is established when the T-score is below $-2.5 .^{5}$ The disadvantage of this definition is that it takes into account defects in bone mineralization without addressing critical changes in bone architecture. Another problem when assessing men's bone mineral density (BMD) is that many laboratories measure T-score using female reference values. Considering that young females have lower bone mass and lower peak areal BMD than their male counterparts, the use of reference values of young men may be of value. However, it can lead to an increasing rate of males being diagnosed as osteoporotic, assuming that the threshold for diagnosis is a T-score below -2.5. This was evident in the NHANES study where $3-6 \%$ of men over the age of 50 were considered osteoporotic and $28-47 \%$ osteopenic when male reference values were used, compared to $1-4 \%$ and $15-33 \%$ corresponding rates when female reference values were established, respectively. ${ }^{6}$ Considering the above, the International Society for Clinical Densitometry (ISCD) recommended in its guidelines the use of 
a database of young adult Caucasian men for the calculation of T- and Z-scores. ${ }^{7}$

Furthermore, we may need to establish new databases based on the different races and possibly adjust the upper limit of the T-score for the diagnosis of male osteoporosis. The need for the latter arises mainly from the fact that a large percentage of men (in several studies over $80 \%$ ) presenting with low energy fractures have a normal T-score. ${ }^{8}$ The osteoporotic threshold shift towards a higher value will lead to a greater number of men being diagnosed with osteoporosis (when BMD is only used for diagnosis).

\section{EPIDEMIOLOGY}

According to the National Osteoporosis Foundation (NOF), in the U.S. in 2002 there were 43.6 million people over the age of 50 with low bone mass, 10.1 million among them being diagnosed with osteoporosis. In 2010, the corresponding figures were 52.4 and 12 million, respectively. Men suffering from osteoporosis were approximately 2.3 million in 2002 and 2.8 million in 2010. In addition, men with low bone mass, though not suffering from osteoporosis, numbered 11.8 million in 2002 and 14.4 in $2010 .^{9}$

Since it is difficult to record the prevalence and incidence of osteoporosis, indirect conclusions can be drawn by measuring the number of osteoporotic fractures and calculating the fracture risk. The risk for a man over the age of 50 years of sustaining any type of osteoporotic fracture during the rest of his life ranges from $13.1 \%$ (in the U.S.) to $22.4 \%$ (in Sweden). Women have a significantly higher risk of suffering a similar fracture (over $53.2 \%$ in the U.K.). Specifically, the risk of hip fracture for men ranges from $3.1 \%$ (U.K.) to $10.7 \%$ (Sweden) and clinical vertebral fracture from $1.2 \%$ (U.K.) to $8.3 \%$ (Sweden). ${ }^{10}$

According to Johnell and Kanis, 8,959 million osteoporotic fractures were measured worldwide in $2000,38.6 \%$ of them (3,463 million) occurring in men. Compared to women, men had fewer hip fractures (30\% of total hip fractures), vertebral fractures (42\% of the total number in this area), forearm and humeral fractures $(20 \%$ and $25 \%$ of the total number, respectively). However, in the rest of the skeleton men sustained a greater number of fractures than women $(54 \%$ vs. $46 \%) .{ }^{1}$
In males, higher mortality has been reported compared to females following a hip fracture ranging from 6 to $50 \% .{ }^{11}$ More specifically, during hospitalization, mortality in men is almost twice that of women, ${ }^{12}$ while in the first month mortality remains significantly higher (12\% in males compared to $7 \%$ in females). ${ }^{13}$ Moreover, men have an increased preoperative mortality rate and experience at least one postoperative complication. ${ }^{12}$ This rate remains higher in men long after the fracture, although the difference is diminished after a 6-month period. ${ }^{14}$ The aetiology of the increased mortality of men compared to women has not as yet been clarified. It has in part been attributed to a higher incidence of co-morbidities in males compared to females, which can lead to more severe postoperative complications such as pneumonia, arrhythmia and pulmonary embolism..$^{12,13}$

In addition, the quality of life is severely compromised following an osteoporotic hip fracture since a large percentage of people cannot return to their previous level of activity and independence. It is interesting that more than $15 \%$ of men sustaining such a fracture are unable to walk two years post-operatively while only $34 \%$ can walk without an aiding device..$^{15}$

By 2050, the European population over 50 years of age is projected to increase by $36 \%$ for men and $26 \%$ for women. The increase will be even greater for those over 80 years old $(239 \%$ and $160 \%$ for men and women, respectively). In these circumstances of a continuous aging of the population, the incidence of osteoporosis and osteoporotic fractures as well as the economic burden of their treatment are expected to rise significantly. It is estimated that the cost of osteoporotic fractures in 2025 and 2050 will reach 54 and 76.8 billion euros, respectively, of which 14.7 and 22.8 billion euros will be spent on male osteoporotic fractures. ${ }^{16}$

In a study in 1997, Gullber et al sought to estimate the incidence of osteoporotic hip fractures globally based on epidemiological data of that time. They concluded that while in 19901.26 million hip fractures had occurred worldwide $(27 \%$ of them among males), in 2025 the estimated number will be 2.6 million fractures (30\% in men) and in 20504.5 million ( $31 \%$ in men). Men will be affected most, with an estimated increase of $310 \%$ of osteoporotic hip 
fractures from 1990 to 2050 . This increase is mainly attributed to the greater increase in life expectancy for men than for women. ${ }^{17}$ However, it is not certain whether these estimates will actually materialize. Although in some countries a steady increase in the incidence of hip fractures is observed, in others the number of these types of fractures remains stable or is even decreasing. ${ }^{18-21}$ Moreover, there is a difference in the incidence between the two sexes and between different age groups. In summary, most studies reveal a tendency to a greater increase of osteoporotic fractures in men compared to women. ${ }^{22-25}$

\section{CLASSIFICATION OF OSTEOPOROSIS IN MEN}

Osteoporosis in men can be classified as primary or secondary depending on the presence of an underlying cause (Table 1). Primary osteoporosis can be further divided into age-related and idiopathic, which latter most commonly appears in younger adult males ( $<60$ years of age). The incidence of secondary osteoporosis in men varies from 30 to $70 \% .^{26} \mathrm{~A}$ Greek study reported the presence of a secondary cause for osteoporosis in men in $43 \%$ of cases. ${ }^{27}$ Thanks to advances in medical technology and proper screening of the population these numbers are likely to increase in the future. The most common causes of secondary male osteoporosis include alcohol abuse, glucocorticoid intake and hypogonadism, these factors having been attributed to up to $45 \%$ of affected men according to some studies. ${ }^{26}$ In the aforementioned Greek study, $11.4 \%$ of cases of secondary osteoporosis were attributed to glucocorticoids and $10 \%$ to hypogonadism. ${ }^{27}$ It is common for more than two factors to co-exist and contribute to the presence of secondary osteoporosis.

\section{PATHOGENESIS OF BONE LOSS IN MEN}

Primary male osteoporosis is divided into agerelated and idiopathic, occurring in younger men. There is controversy in the literature concerning the age limit for the definition of idiopathic osteoporosis. Some authors report that the age of 60 years should be used, ${ }^{28}$ while others propose that the age of 65 or even 70 years would be more appropriate. ${ }^{8,26}$ Taking into account that the age-related changes in the male skeleton occur early in adult life and that failure to achieve adequate peak bone mass at a young age is one of the factors leading to osteoporosis, the pathogenesis of these two types of primary male osteoporosis is

TABLE 1. Classification of osteoporosis in men

\section{PRIMARY}

- Age-related

- Idiopathic

II. SECONDARY due to:

A. Endocrine disorders

- Hypercortisolaemia (e.g. Cushing's syndrome)

- Hypogonadism

- Hyperparathyroidism

- Hyperthyroidism

- Diabetes mellitus (type 1and 2)

B. Gastrointestinal disorders

- Malabsorption syndromes

- Inflammatory bowel disease (Crohn's disease, ulcerative colitis, celiac disease)

- Primary biliary cirrhosis

- Liver failure

- Gastrectomy

C. Medication

- Glucocorticosteroids

- GnRH-analogues

- Thyroid hormones

- Anticonvulsants

- Chemotherapy

- Anticoagulants

- Antidiabetics

D. Systematic diseases

- Rheumatoid arthritis

- Ancylosing spondylitis

- Systemic mastocytosis

- Neoplasms (e.g. multiple myeloma)

E. Genetic diseases

- Osteogenesis imperfecta

- Cystic fibrosis

- Homozygous $\beta$-thalassaemia

- Sickle cell anaemia

- Homocystinuria

F. Various conditions

- Renal failure

- Idiopathic hypercalciuria

- Chronic obstructive pulmonary disease

- Transplantation

- Neuromuscular diseases

- Immobilization

- Alcoholism

- Smoking

- Malnutrition 
examined as a whole. The age-related type is characterized by both quantitative and qualitative bone disorders. These are mainly attributed to changes in the concentration of circulating endogenous factors which regulate bone metabolism. When these changes are severe, they can lead to bone loss greater than expected.

\section{BMD and bone size changes in men during aging}

Quantitative computed tomography, especially with the use of high resolution imaging technology (HR-QCT and HR-pQCT), made it possible to study in detail the effect of aging on bone mass and geometry in males.

Males have larger skeletal size and greater bone mass than females in young adulthood (25-33\% and $18-21 \%$ greater bone area and BMD, respectively). These differences remain unchanged during aging. An increase in bone area of $7-15 \%$ is observed in the lumbar spine and femoral neck in both sexes. In other parts of the skeleton, such as the tibia and radius, an increase of $2-16 \%$ is evident. ${ }^{29,30}$

It seems that loss of volumetric BMD (vBMD) begins early in adulthood, during the third and fourth decade, occurring mostly in cancellous bone. There is a greater loss of vBMD in the axial skeleton in women compared to men ( 55 vs. $46 \%$ ), while in the appendicular skeleton there is almost no difference (24vs. 26\%). ${ }^{29}$ Moreover, the loss of cancellous vBMD occurs earlier in women, mainly during the early postmenopausal years. ${ }^{29}$ Approximately $42 \%$ of the total loss of trabecular vBMD in men occurs before the age of 50. The rate of reduction remains almost constant throughout adult life for the appendicular skeleton, with the exception of the third decade when it is slightly elevated. By contrast, in the lumbar spine the rate of trabecular bone loss doubles after the age of 50 with the highest rates observed after the age of $70 . .^{31}$

Cortical bone loss also occurs during aging but it is mostly evident after middle age in both sexes. Cortical vBMD reduction is greater in women ( $28 \%$ vs. $18 \%$ ) and occurs later in life. ${ }^{29,31}$ In men, only $15 \%$ of the total bone loss observed occurs before the age of 50 . The rate of reduction of cortical vBMD increases 2 to 4 times after that age and peaks after $75 .{ }^{31}$
Periosteal bone apposition is a normal process during aging and increases bone size in both sexes. An increase in long tubular bone diameter results in improved mechanical bone strength. Endosteal bone resorption occurs along the inner edge of the cortex at the same time. As bone resorption rate is greater than bone formation rate, a lower cross-sectional cortical area is observed. Riggs et al reported that endocortical resorption, as expressed by expansion of the marrow space, was greater in women than in men at the proximal femur (38\% vs. $25 \%$, respectively), but these differences were not statistically significant. ${ }^{29}$ Lauretani et al, in a population-based study, found a 4-fold higher expansion in the medullary area at the tibia in women than in men in all age groups $(114 \%$ vs. $30 \%) .{ }^{32}$ Thus, although young men have a larger medullary area than women, the widening in the medullary canal becomes steeper in women with age. Conversely, an increase in total bone area is almost 2 -fold higher in men than women (9\% vs 5.7\%). ${ }^{32}$

In summary, it seems that there is slight thinning of the cortex in men compared to women. It would appear that in men up to the age of 70 the cortical bone area increases. ${ }^{32}$ Similar findings are evident at the distal radius level but the differences are not equally significant. ${ }^{30}$ Interestingly, this phenomenon is even greater in the femoral diaphysis compared to the femoral neck. It has been found that the crosssectional area of the femoral neck is higher by $1.6 \%$ in men over 85 years compared to men of 65 to 69 years of age. In femoral diaphysis this rate is $8.9 \% .^{33}$

\section{Changes in bone microarchitecture of men compared with age}

Using high resolution 3D-pQCT at the distal radius, the effects of sex and age on bone microarchitecture have been examined. It was observed that trabecular BV/TV is greater in men than in women but decreases with age at a similar rate in both sexes. ${ }^{30}$ However, there is a structural difference of the decrease in trabecular volume between men and women. Women undergo loss of trabeculae with age, whereas men sustain primarily trabecular thinning and an increase of trabeculae number. ${ }^{30}$

In men between the ages of 20 and 49, trabecular number increases by $13.6 \%$ and then decreases by $8.2 \%$ until the age of 90 . However, trabecular thickness 
decreases by $25.9 \%$ between 20 and 49 years and is accompanied by a significant decrease in trabecular separation by $8.2 \% .{ }^{30} \mathrm{Via}$ this mechanism, the male skeleton compensates for cancellous bone loss, since we know that decreases in the number of trabeculae has a 2 to 5 times greater effect on the mechanical properties of bone than a decrease of trabecular thickness which causes the same loss of bone volume. ${ }^{34}$

These findings are consistent with earlier studies which were based on histomorphometric analysis in normal bone using iliac crest specimens. ${ }^{35}$ Therefore, it is likely that the above model can be applied to the whole male skeleton, in which case it would explain the lower incidence of fractures in men compared to women with age.

Regarding the cortical bone changes in microarchitecture, limited data are available. It is considered that porosity increases in both sexes, mainly due to an increase of bone resorption associated with an inadequate remodelling of the osteons that have been destroyed during the aging process. ${ }^{29}$

\section{Effect of sex hormones on the male skeleton}

Bone forming cells contain both androgen (AR) and estrogen (ER $\alpha, E R \beta)$ receptors along with enzymes involved in sex hormones metabolism, such as aromatase 5a-reductase, 17b-dehydrogenase and 3b-dehydrogenase. It appears that both types of steroids play a role in bone growth. Estrogen, particularly via ER $\alpha$ receptors and possibly mediated by changes in the concentration of IGF-1, favour the longitudinal growth of long bones in the epiphyseal plate. Androgens, on the other hand, stimulate periosteal apposition and are responsible for appositional growth which indicates an increase in bone thickness or mass. Sex hormones also play an important role in maintaining bone mass with age: estrogen protects both cancellous and cortical bone and androgen mostly cancellous bone. ${ }^{36}$

With aging, testosterone and $17 \beta$-estradiol levels decline and sex hormone binding globulin (SHBG) levels increase. ${ }^{37-40} \mathrm{An}$ MrOS study showed that both total and bioavailable testosterone levels are diminished with aging and a $10 \%$ reduction rate per decade was reported. Moreover, there was a strong correlation between older age and low rates of total and bioavailable estradiol. Additionally, low levels of free estradiol were associated with low free testosterone and high SHBG. ${ }^{38}$

A number of studies report a strong correlation of such sex steroid changes with increased bone loss during aging. In the MrOS study, it was observed that the incidence of osteoporosis in men over 65 with low levels of total testosterone $(<200 \mathrm{ng} / \mathrm{dl})$ was $12.3 \%$, while in those with normal levels (>400ng/ dl) it was $6 \%$. Likewise, in men with low $(<10 \mathrm{pg} /$ $\mathrm{ml})$ and normal values of total estradiol $(>20 \mathrm{pg} /$ $\mathrm{ml}$ ), the incidence of osteoporosis was $15.4 \%$ and $2.8 \%$, respectively. This finding indicates a strong correlation between low total estradiol and low BMD. Additionally, it was noted that among osteoporotic men, $6.9 \%$ of them had total testosterone $<200 \mathrm{ng} / \mathrm{dl}$ and $9.2 \%$ total estradiol $<10 \mathrm{pg} / \mathrm{ml}$. Similar findings were reported for the bioavailable fractions. On the other hand, low total and bioavailable testosterone correlated more strongly with accelerated bone loss ( $>3 \%$ per year) at the hip than low total and bioavailable estradiol levels. ${ }^{41}$

Falahati-Nini et $\mathrm{al}^{42}$ and Leder et $\mathrm{al}^{43}$ demonstrated the independent role of estrogens and androgens on bone metabolism in healthy men by creating a selective deficiency of sex steroids. The first study (in normal elderly men) found that estrogens were responsible for over $70 \%$ of sex hormone-related bone resorption, while bone formation was equally affected by both types of steroids. ${ }^{42}$ The study by Leder et al (in normal young men) demonstrated superiority of androgens in bone formation and independent action of both hormones on bone resorption. ${ }^{43}$

Using quantitative computed tomography (QCT), Khosla et al sought to correlate the levels of bioavailable testosterone and estradiol with vBMD and bone geometry parameters in an age-stratified male population. ${ }^{37}$ They found that in young men with high levels of the bioavailable fractions, these were not related to the parameters tested. In older men, lower levels of these fractions were associated with both vBMD values and bone geometry measurements. In general, bioavailable estradiol seemed to have a greater effect in most parameters measured compared to bioavailable testosterone. This was evident for vBMD values at all measuring points (lumbar spine, hip, distal end 
of the tibia and radius) with the exception of vBMD measurements at the femoral neck (greater correlation with bioavailable testosterone), on the surface of cortical bone (positive correlation) and subcortical surface (negative correlation). It seems that there might be a bioavailable estradiol level threshold $(' 8 \mathrm{pg} / \mathrm{ml})$ below which a clear effect on the skeleton is observed. This threshold applies mainly to the cortical bone and is probably higher for the trabecular bone, possibly due to the fact that trabecular bone cells express a greater proportion of ER $\beta$ compared to cortical bone. Taking into account that ER $\beta$ play a minor role in bone metabolism compared to $\mathrm{ER} \alpha$, greater concentrations of estrogen in cancellous than in cortical bone are needed to obtain the same estrogenic effect in both bone types. ${ }^{44}$

The effect of sex hormones on the male skeleton was further examined in several studies that have correlated low levels of these hormones with an increased fracture risk. ${ }^{40,45}$

Several studies show that testosterone is not strongly associated with bone loss, while others refer to it as a strong predisposing factor for osteoporotic fractures. A possible explanation is that the hormone affects mostly exoskeletal parameters of fracture risk. Adequate levels of the hormone ensure good mental health, normal function of the muscular system by maintaining muscle mass and strength and normal body balance, protecting from falls, which constitutes an important predisposing factor for fractures. ${ }^{45-48}$ However, some of these effects have been attributed to its aromatization to estrogens. ${ }^{49}$

The undoubted effect of estradiol (total, free or bioavailable) on the male skeleton led us to the conclusion that the pathogenesis of bone loss in men is closely related to its production and factors associated with its action. The pathogenesis of male osteoporosis is consequently related to quantitative and qualitative changes of aromatase and estrogen receptors which mainly arise from genetic variations of the corresponding genes. Men with mutations in the gene of the estrogen receptor $(E R \alpha)$ and the gene of aromatase (CYP19) present with very low BMD values due to hormone deficiency. ${ }^{44}$ In addition, polymorphisms in the gene for aromatase appear to alter the activity of the enzyme with similar effects on BMD. ${ }^{36,50}$ Larger studies focusing on the location of these genetic polymorphisms will probably shed more light on the pathogenesis of bone loss in men.

Finally, a threshold estradiol level below which fracture risk is increased is shown in several of the above studies ${ }^{37,40,45,47}$ Determining the exact level and its clinical use is definitely a matter for future investigation.

\section{Effect of other hormones and endogenous factors}

\section{Growth hormone (GH) - Insulin-like growth factor 1 (IGF-1)}

GH and IGF-1 have an anabolic effect on skeletal growth. Their receptors in growth plate chondrocytes stimulate longitudinal bone growth with endochondral bone formation. Cell receptors for GH and IGF-1 are also found on both osteoblasts and osteoclasts. ${ }^{51}$

GH stimulates proliferation of osteoblasts and differentiation of progenitor mesenchymal stem cells to osteoblasts rather than adipocytes. Moreover, it promotes osteoblast differentiation and function of mature osteoblasts by increasing production of bone morphogenetic proteins (BMPs) and osteoprotegerin (OPG). Apart from its direct effect on bone metabolism, GH influences the circadian rhythm of parathyroid hormone (PTH) secretion, probably by increasing renal resorption of phosphorus. It also increases the production of $1,25(\mathrm{OH})_{2} \mathrm{D}_{3}$ with the induction of 1a-hydroxylase and inhibition of 24-hydroxylase. ${ }^{51}$

IGF-1 is produced in osteoblasts under the effect of various factors such as $\mathrm{PTH}$, estrogens, thyroid hormones and BMP2. Factors that inhibit its production include glucocorticoids and platelet derived growth factor. It is likely that the effect of these factors on bone metabolism is mostly achieved through changes in local IGF-1 concentrations. The main role of IGF-1 in bone is the stimulation of osteoblasts. It increases the synthesis of type I collagen, while reducing the synthesis of collagenase 3 in favour of bone formation. In contrast, it seems that it does not significantly affect osteoblastogenesis and differentiation into mature osteoblasts. In addition, IGF-1 stimulates osteoclastic bone resorption and increases RANKL production, thus promoting osteoclastogenesis. ${ }^{51}$

With aging, GH and IGF-1 levels are reduced. ${ }^{52}$ Especially in men, daily GH secretion may be im- 
paired in the elderly, reaching only $1 / 20$ of its levels encountered in young adults. ${ }^{53}$ Compared to women, the rate of its level reduction in men is twice as fast. This results in higher GH secretion levels in women than in men after the age of $50 . .^{5}$

Most of systemic and local IGF-1 is bound to specific binding proteins (IGFBPs), which act primarily as IGF- 1 carriers, though they also have the ability to modify its function. The fact that they inhibit IGF-1 function means that they are likely involved in the pathogenesis of osteoporosis. It has been found that IGFBP-2 increases significantly with aging in both men and women and is negatively correlated with $\mathrm{BMD}^{54}$ and positively with bone turnover biochemical markers. ${ }^{54}$ It was also noted that IGFBP-3, the main IGF-1 carrier in the systemic circulation, decreases with age. The concomitant decrease in IGF-1 is associated more than any other factor with the changes observed in cancellous bone in men during the first two decades of adult life. Later in life these changes are mainly attributed to sex hormones. ${ }^{52}$

Finally, our observations to date (mainly in transgenic mice but also in humans with GH deficiency) suggest that IGF-1 in systemic circulation is responsible for the maintenance of cortical bone mass, while locally produced IGF-1 acts by protecting cancellous bone. ${ }^{51}$

\section{Endogenous factors associated with adipose tissue}

The finding that body weight and body mass index are crucial factors of BMD and fracture risk,,${ }^{55,56}$ with overweight people having higher BMD and lower risk of a fragility fracture, led to an attempt to explain the possible connection between adipose tissue and the pathogenesis of bone loss. Possible mechanisms which may explain an increase in BMD in overweight individuals include excessive bone loading and fat tissue production of bone-protective factors. Greater bone loading results in positive changes in bone mass and structure. Aromatization of androgens to estrogens is increased in individuals with a large amount of fat tissue, with the aforementioned benefits to male skeleton. However, other substances with a potential significant effect on bone such as leptin and adiponectin are secreted in adipocytes.

Leptin is an adipocyte hormone and affects bone metabolism both by acting directly on bone cells and indirectly mediated by the central nervous system. Most of the data available about its role on bone metabolism have been obtained from animal studies and primary cultured human bone cells. Leptin causes induction of proliferation and differentiation of osteoblasts, ${ }^{57,58}$ inhibits RANKL production and increases OPG production, leading to inhibition of osteoclastogenesis. ${ }^{59}$ The final result of its peripheral action is increased bone mass.

In contrast, systemic leptin administration seems to decrease BMD. The main target is the mediobasal hypothalamus and in particular the arcuate nucleus, where energy balance is regulated (balance between energy requirements and food intake). Through a complex system of inhibition and induction of different pathways, mostly via the sympathetic nervous system, leptin increases the fullness feeling, leading to lower food intake and weight loss with similar effects on BMD. Through its indirect action on $\beta$-adrenergic receptors in osteoblasts, bone formation is inhibited and osteoclastic activity is increased..$^{60,61}$

The overall effect of leptin on bone mass appears to be positive since its peripheral action prevails over its systemic in most cases. ${ }^{62}$ In addition, systemic administration of the hormone in leptin-deficient animals led to a dose-dependent response (lower doses-equal to normal serum levels-have a beneficial effect on bone, while higher doses cause significant loss of weight and bone mass). ${ }^{63}$

There are limited data about the role of leptin in the human skeleton. Most of the studies to date agree on its positive effect on bone. ${ }^{62}$ Although the majority of these studies involve female populations, it is likely that the same principles apply to men. They conclude that changes in leptin levels in humans may be a possible cause of osteoporosis.

Adiponectin is an adipose derived hormone. In contrast to leptin, its secretion decreases with increased body fat mass. ${ }^{62}$ Its role in bone metabolism has not yet been completely clarified but the existing data support a dual action: it induces osteoblast differentiation, though mainly osteoclastogenesis, by increasing the production of RANKL and decreasing OPG secretion from osteoblasts. ${ }^{64,65}$ It has been stated that individuals with low body fat mass have higher levels of adiponectin, resulting in bone loss due 
to the action of osteoclasts. A recent study in men over 60 years found that the hormone was negatively correlated with body mass index and BMD at the lumbar spine and femoral neck and positively with age. ${ }^{66}$ These findings suggest that increased levels of adiponectin may also be a cause of male age-related osteoporosis.

Except for factors secreted directly by adipocytes, other substances whose production is regulated indirectly by adipose tissue may affect bone metabolism. A typical example is insulin. In cases of increased body fat mass increased insulin resistance is observed. To compensate, pancreatic B-cell hypersecrete insulin, resulting in hyperinsulinaemia. This causes increased production of sex hormones and reduced SHBG production, with the consequences mentioned above. Moreover, insulin, amylin and preptin, all secreted from pancreatic B-cells, have a direct anabolic effect on osteoblasts (inducing their proliferation). As a result, increased body fat mass leads to an increase in bone mass by changing the secretory function of pancreatic cells. ${ }^{62}$ In men, insulin sensitivity (which is accompanied by low levels of the hormone) is negatively correlated with BMD. In the same study, the association between BMD and body fat mass was lost after adjustment for insulin sensitivity, suggesting that the relationship of fat-bone mass is mediated by the action of insulin. ${ }^{67}$ Considering the above, we can assume that in cases of low insulin levels, lower BMD values can be observed and may partly explain the pathogenesis of primary male osteoporosis.

\section{DIAGNOSIS}

The diagnosis of osteoporosis in men is based on the same fundamental principles as the diagnosis of other diseases: careful exploration of the patient's medical history, physical examination and paraclinical investigations. These will help establish correct diagnosis, identify possible causes of secondary osteoporosis and assess fracture risk, an important factor of the decision for the treatment decision-making process.

\section{Medical history and physical examination}

The patient's medical history can provide important information about possible risk factors for bone loss, the presence of an osteoporotic fracture or atypical symptoms and signs such as back pain (indicative of potential spinal deformity), height loss (indicative of multiple vertebral deformations) or symptoms indicative of diseases that may cause secondary osteoporosis and have not yet been diagnosed. It is strongly recommended to insist on family history, history of previous fracture in any member of the family involved, chronic illnesses, type of medications used, lifestyle (diet, smoking, alcohol, exercise) and history of falls. ${ }^{8}$

A recent systematic review of the literature which aimed at identifying the most important risk factors for osteoporotic fractures in men concluded that the main risk factors are age over 70 years, low body weight (body mass index $(\mathrm{BMI})<20 \mathrm{~kg} / \mathrm{m}^{2}$ ), weight loss $(>10 \%)$, limited physical activity and previous osteoporotic fracture. Data on other risk factors such as smoking (moderate risk factor for loss of BMD and less important risk factor for fracture) and alcohol (moderate risk factor for fracture and less important risk factor for loss of BMD) were not so reliable. ${ }^{68}$

Physical examination offers little information to help diagnosis since the disease is mostly asymptomatic. An osteoporotic fracture may be the first clinical manifestation and leads to a diagnostic work-out for osteoporosis. Kyphotic deformities of the spine or localized pain on palpation of the spine may occur and lead to further investigation. In any case, height, weight and BMI should be measured and a screening for secondary causes of osteoporosis must always be performed. ${ }^{8}$

\section{Paraclinical investigations}

These include bone densitometry, conventional spine radiographs, blood and urine tests and urine and, in rare cases, histomorphometry after bone biopsy.

\section{Bone densitometry}

Bone densitometry using DXA is the method of choice for the diagnosis of male osteoporosis. According to the official statement of the ISCD, BMD testing is indicated in men over the age of 70 years, men younger than 70 years with clinical risk factors for fracture, men with a history of a fragility fracture, men suffering from a chronic disease or condition associated with low BMD or bone loss and all patients who are going to start on prophylactic treatment for 
osteoporosis or are already being treated for the disease (to assess the therapeutic effect). ${ }^{7}$ It is recommended to use a database of young adult Caucasian men for the calculation of T-scores. ${ }^{7}$

WHO criteria for the diagnosis of osteoporosis use the DXAT-score, but this only applies to men over 50 years. For younger men, the $\mathrm{Z}$-score is used and a threshold value of -2 makes the distinction between "values within the expected range for age" (Z-score $>-2$ ) and "values below the expected range for age" (Z-score $\leq-2$ ), in which case the terms "osteoporosis" and "osteopenia" (low bone mass) are not appropriate. To set the diagnosis of osteoporosis by DXA, we measure the T-score of the lumbar spine, total hip, femoral neck and $33 \%$ of the radius. The recommendation of the ISCD is to definitely do the measurements in the lumbar spine and non-dominant hip, while the measurement of the non-dominant radius should be performed if it is not possible to measure bone mass at the aforementioned sites or in cases of hyperparathyroidism or extremely obese patients (over the weight limit of the table of the device). ${ }^{7}$

Other methods of bone densitometry [QCT, pQCT, peripheral DXA (pDXA), quantitative ultrasound (QUS)] cannot be used for the diagnosis of osteoporosis in men, with the exception of radial pDXA. However, trabecular BMD in the lumbar spine, measured with QCT, can be used to monitor changes associated with age, a medical condition or treatment. Total BMD and trabecular BMD measured by pQCT at the distal radius may be used to monitor age-related changes in BMD. Additionally, QUS of the heel can predict fragility fractures (hip and non-vertebral) in men over 65 years irrespective of the BMD values in DXA. Furthermore, QUS and pDXA measurements when combined with clinical risk factors can lead to the identification of individuals at very low risk for fracture thus avoiding the need for any other diagnostic procedure, while in cases where DXA cannot be performed they may lead to the decision to treat if the calculated fracture risk is high. ${ }^{7}$

\section{Plain radiographs}

Plain radiographs of the spine are used in addition to physical examination, clarifying whether there is an osteoporotic fracture or not in cases of back pain. They can also reveal "silent" vertebral deformities and help differential diagnosis of other conditions such as Sheuermann disease. ${ }^{8}$ Finally, radiographs may act as a trigger for further investigation, since it is possible to highlight osteoporotic bones.

\section{Blood and urine laboratory tests}

Laboratory blood and urine tests are mainly used in men with low BMD or fragility fractures in order to identify possible causes of the disorder of bone metabolism. They help to differentiate osteoporosis from other osteopenic conditions such as osteomalacia and identify secondary causes of osteoporosis.

In cases where a patient's history and physical examination do not provide enough information to guide laboratory testing, a number of tests are routinely performed (Table 2). These include complete blood count $(\mathrm{CBC})$, erythrocyte sedimentation rate (ESR), serum calcium and albumin (for evaluation of bioavailable calcium), serum creatinine, phos-

TABLE 2. Laboratory investigation for men with low bone mass

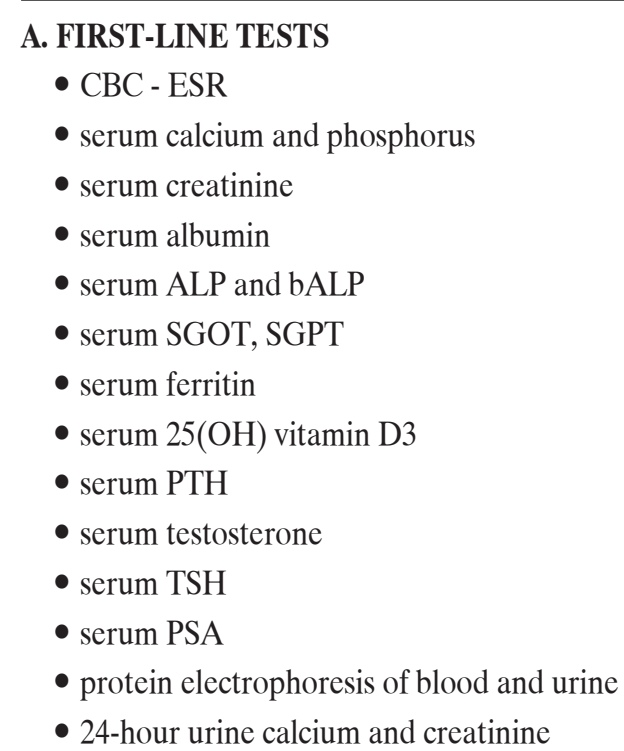

\section{B. SECOND-LINE TESTS}

- 24-hour urine free cortisol

- urine N-methylhistamine

- serum IgA autoantibodies against transglutaminase

- serum LH

- serum prolactin

- serum estradiol

- serum SHBG

- biochemical markers of bone metabolism 
phorus, serum alkaline phosphatase levels (ALP) along with its bone isoenzyme (bALP), transaminases (SGOT, SGPT) and ferritin (to exclude the diagnosis of haemochromatosis and chronic liver damage), $25(\mathrm{OH})$ vitamin $\mathrm{D}_{3}$, parathyroid hormone $(\mathrm{PTH})$, serum testosterone, thyroid stimulating hormone (TSH) (to exclude hyperparathyroidism, hypogonadism and hyperthyroidism, respectively), protein electrophoresis of blood and urine (for exclusion of multiple myeloma) and prostate specific antigen (PSA). Finally, 24-hour urine calcium and creatinine should be measured for the assessment of idiopathic hypercalciuria ( $\mathrm{Ca} \mathrm{U} 24 \mathrm{~h}>300 \mathrm{mg}$ ) and hypocalciuria (Ca U 24h $<100 \mathrm{mg}$ ), which is indicative of low intake or impaired absorption of calcium (in cases without calcium-sparing diuretic intake).

A second set of tests should be ordered if the above fail to reveal the aetiology of the disorder of bone metabolism (Table 2). The 24-hour urine free cortisol will investigate the presence of Cushing's syndrome, whereas urine N-methylhistamine will help set the diagnosis of mastocytosis. Moreover, serum IgA autoantibodies against transglutaminase will lead to the diagnosis of celiac disease. In men with androgen insufficiency, serum luteinizing hormone (LH) and prolactin levels should be measured to help differentiate primary from secondary hypogonadism and identify a possible prolactinoma. Finally, there is controversy as to whether laboratory testing should include measurements of estradiol and SHBG levels (as well as bioavailable estradiol and testosterone).

Biochemical markers of bone metabolism, though they do not seem to be associated with fracture risk in men irrespective of $\mathrm{BMD},{ }^{69}$ are not used for diagnosis but mainly for monitoring of osteoporotic men and detecting response to treatment. ${ }^{70}$

\section{Histomorphometry}

Histomorphometry is the most reliable method for diagnosing osteoporosis and differentiating it from other disorders of bone metabolism such as osteomalacia and adynamic bone disease. Its limited use is due to the fact that it requires iliac crest bone biopsy. Thus it is only recommended in severe cases of osteoporosis where no clear cause has been found.

A summary of the above is shown in Figure 1.

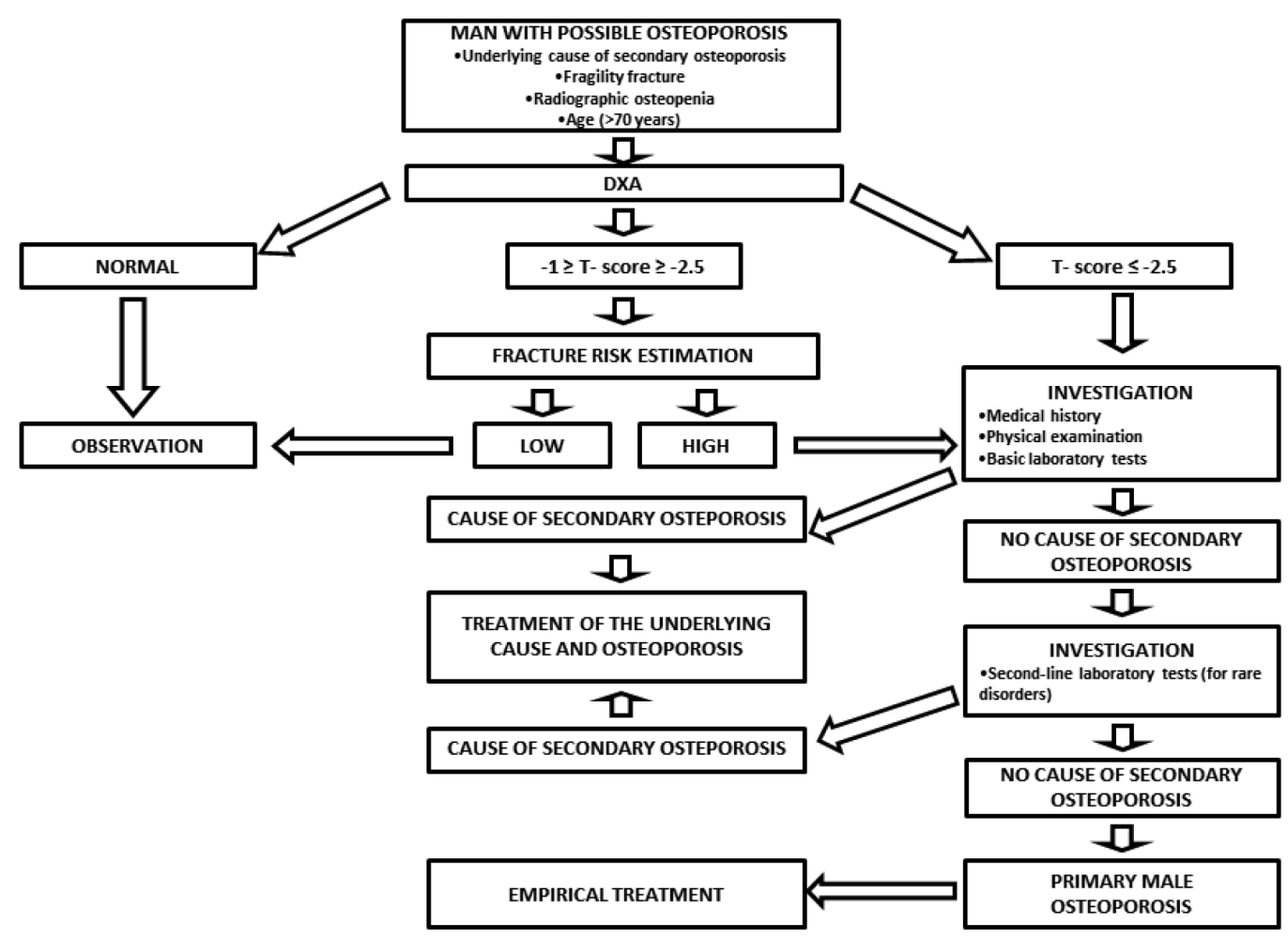

Figure 1. Management algorithm for men with possible osteoporosis. 


\section{PREVENTION}

There is no difference in the prevention of osteoporosis between men and women. The principal aim is to identify and manage possible secondary causes of the disease and modify the individual's lifestyle. Lifestyle factors which should be addressed include diet (adequate calcium intake is crucial), adequate sun exposure to increase vitamin D levels, smoking and alcohol cessation and physical activity.

Treatment of secondary causes of osteoporosis is essential to prevent the development of the disease. In cases where factors that potentially cause osteoporosis cannot be avoided (for example, in cases of corticosteroid intake), treatment is initiated to prevent the disease. Vitamin D and calcium levels should be monitored and when satisfactory levels cannot be achieved with diet and sun exposure, supplements must be prescribed. The optimal vitamin D status has not yet been determined in men. Some argue that $1200 \mathrm{mg}$ of calcium per day plus 800IU of vitamin D is adequate (US Institute of Medicine), while others raise the optimal dosage to $1000 \mathrm{IU}$ per day. ${ }^{71}$ In the past it was suggested that daily calcium intake should not exceed $1500 \mathrm{mg}$ in men over $65 .{ }^{72}$ Conflicting evidence exists concerning the effect of calcium and/ or vitamin D supplements on fracture risk and BMD. Two recent meta-analyses suggest that the combination of the two factors actually reduces the risk of fracture in both men and women. ${ }^{73,74}$ It appears that these supplements are most effective in men with calcium and vitamin D deficiency, those on glucocorticoid treatment, those on anabolic anti-osteoporotic treatment or treatment with anti-osteoclastic agents, those receiving $800 \mathrm{IU}$ vitamin D and $1000-1200 \mathrm{mg}$ of calcium per day and compliant patients. ${ }^{75}$

\section{TREATMENT}

There are few randomized controlled studies on the treatment of osteoporosis in men. Moreover, the majority of these studies involve a small number of patients and mostly measure changes in BMD, while the incidence of fractures and fracture risk are rarely addressed. However, certain drugs have been tested in men with similar efficacy and safety as those administered to postmenopausal women. To date, the Food and Drug Administration (FDA) and the European Medicines Agency have approved the use of alendronate, risedronate, zoledronic acid, teriparatide and strontium ranelate for the treatment of osteoporosis in men. In any case, drug treatment of male osteoporosis should be combined with the preventive measures mentioned above and an adequate intake of calcium and vitamin D.

\section{Bisphosphonates}

Bisphosphonates are the most widely used drugs for the prevention and treatment of bone loss in men. They inhibit the mevalonic acid pathway and osteoclast activity, thus reducing the rate of bone turnover and ultimately increasing bone density.

\section{Alendronate}

In a study of 241 men, aged 31 to 87 years, with T-score $\leq-2$ (at the femoral neck or lumbar spine), administration of $10 \mathrm{mg}$ alendronate peros (p.o.) daily (along with $500 \mathrm{mg}$ calcium and 400IU vitamin D) for two years resulted in a significant increase in BMD of the lumbar spine in comparison to the group receiving placebo. ${ }^{76}$ Although the study was not designed to assess the effect of the drug on fracture risk, it showed that men who received alendronate had fewer vertebral fractures than those on placebo treatment. ${ }^{76}$ A similar effect on BMD of the lumbar spine and hip was observed when weekly p.o. administration of $70 \mathrm{mg}$ alendronate was used. ${ }^{77}$ Finally, in a small open-label study, daily p.o. administration of alendronate in men with low bone density was found to be superior to alphacalcidol in terms of BMD increases in the lumbar spine and number of vertebral fractures three years after the initiation of treatment. ${ }^{78}$ Alendronate is also effective in the treatment of secondary male osteoporosis, such as that which is glucocorticoid-induced. ${ }^{79}$

\section{Risedronate}

Similar findings have been noted when risedronate was used for the prevention and treatment of male osteoporosis. In a randomized double-blind multicenter study in which 284 men participated, it was found that after two years of treatment with p.o. administration of risedronate $35 \mathrm{mg}$ once weekly, in combination with daily administration of calcium and vitamin $\mathrm{D}, \mathrm{BMD}$ significantly increased at the lumbar spine compared with placebo (6\% versus $1.4 \%$ at 24 months). The 
same effect on BMD was evident in other parts of the skeleton. ${ }^{80}$ Risedronate provided a rapid beneficial effect, as noted by the suppression of biomarkers of bone turnover in the first trimester of administration and DXA measurements after a six-month treatment period. Its effect was independent of age and history of previous vertebral fracture. However, there was no difference in the incidence of new vertebral fractures. ${ }^{80}$ A similar effect on BMD was obtained with a daily dose of $5 \mathrm{mg}$ p.o. (with supplementary use of calcium and vitamin D) as observed in a twoyear randomized open-label study of 316 men with primary and secondary osteoporosis. ${ }^{81}$ In this study, the beneficial role of the drug in the presence of an osteoporotic fracture was highlighted. The rate of vertebral and non-vertebral fractures among recipients of risedronate was reduced compared to men on placebo therapy $(9.2 \%$ and $11.8 \%$ versus $23.6 \%$ and $22.3 \%$, respectively). ${ }^{81}$ Finally, in a study of 280 men, aged 65 years, with a history of stroke, daily p.o. administration of risedronate reduced significantly the risk of hip fracture compared to placebo. ${ }^{82}$

\section{Zoledronic acid}

Intravenous (IV) bisphosphonates, such as zoledronic acid, have better bioavailability than oral bisphosphonates, are recommended for patients who are unable to take oral medications and have lower incidence of upper gastrointestinal side effects and better adherence to treatment since a once-yearly infusion is needed. In the HORIZON study (Health Outcomes and Reduced Incidence with Zoledronic acid Once yearly), 2127 patients (24\% were men) were randomized to receive either a once-yearly IV infusion of zoledronic acid $5 \mathrm{mg}$ or placebo treatment. Participants had experienced a low energy hip fracture, which was treated surgically, and received the first dose of the drug within the first 90 days after surgery. After 36 months of treatment, patients treated with zoledronic acid significantly increased their BMD at the hip compared to the placebo group. Most importantly, in men receiving the drug, there was a $46 \%$ and $27 \%$ reduction of vertebral and nonvertebral fracture risk, respectively, compared with patients who received placebo. For any type of fracture, a $35 \%$ reduction of fracture risk was measured and a $28 \%$ reduction in the number of deaths from any cause. ${ }^{83}$ The FDA approved the marketing of zoledronic injection based mainly on the results of a multicenter, double-blind, randomized study of 302 men who received either $70 \mathrm{mg}$ alendronate p.o. once weekly or $5 \mathrm{mg}$ zoledronic acid IV once yearly for a period of two years. Although according to this study similar effects on BMD increase in the lumbar spine and hip and decrease of bone turnover markers were observed in both groups, $74 \%$ of the participants preferred a once yearly zoledronic acid infusion to weekly oral alendronate therapy ${ }^{84}$ Finally, in a recent study of 1199 men aged 50 to 85 with primary or secondary osteoporosis due to hypogonadism, treatment with $5 \mathrm{mg}$ zoledronic acid IV once a year reduced the risk of new vertebral fractures by $67 \%$ compared with placebo. ${ }^{85}$

\section{Teriparatide}

The finding that intermittent administration of PTH has beneficial effects on BMD, in contrast to the bone loss caused by continuous exposure to high hormone levels, led to the use of its analog [recombinant human PTH (1-34)] teriparatide for the treatment of osteoporosis. Teriparatide is indicated for patients with severe osteoporosis at particularly high risk for fracture. The largest study to date randomized 437 men with primary or secondary osteoporosis due to hypogonadism to daily injections of placebo or teriparatide 20 or $40 \mu \mathrm{g} .{ }^{86}$ All patients received calcium and vitamin D supplements. The mean duration of therapy was 11 months (from 2 to 15 months), though the study was stopped by the sponsor due to an increased number of osteosarcoma cases in experimental animals treated with teriparatide. Increased BMD at the lumbar spine by $5.9 \%(20 \mu \mathrm{g})$ and $9.0 \%(40 \mu \mathrm{g})$, respectively, was observed. These results were statistically significant compared to those of patients who received placebo. This effect of the drug was evident after three months of teriparatide therapy as indicated by measurements of biochemical markers of bone metabolism and bone density. The extension of this study included 355 men who were followed for 30 months. ${ }^{87}$ A number of patients continued on anti-resorptive treatment or testosterone therapy, while others remained untreated. BMD measurements in the lumbar spine and hip for both groups on teriparatide treatment were significantly greater compared to the placebo group at 18 and 30 months follow-up. However, after discontinuation of 
teriparatide there was a gradual decrease in BMD. When bisphosphonates were prescribed after discontinuation of teriparatide, an additional increase in lumbar spine and hip BMD was measured. Finally, the incidence of new vertebral fractures was lower for patients who received teriparatide compared with the placebo group $5.4 \%$ of patients treated with teriparatide $20 \mu \mathrm{g}, 6 \%$ of those treated with a dose of $40 \mu \mathrm{g}$ and $11.7 \%$ of the placebo group), while the incidence of moderate or severe fracture was reduced by $83 \%$ in the teriparatide treated groups. ${ }^{87}$

\section{Denosumab}

Denosumab is a fully human monoclonal antibody to the receptor activator of nuclear factor- $x \mathrm{~B}$ ligand (RANKL) that binds RANK, thus inhibiting osteoclast formation, activation and differentiation. It has been approved for the treatment of men receiving androgen deprivation therapy for prostate cancer. The FDA approved its use based on a multicenter, double-blind study on 1468 men with non-metastatic prostate cancer who received androgen deprivation therapy. The patients were randomized to receive denosumab at a dose of $60 \mathrm{mg}$ subcutaneously every 6 months or placebo. At 24 months, there was a 5.6\% increase in BMD of the lumbar spine in the denosumab group, while the placebo group showed a decrease of $1 \%$. Similar increases in BMD were measured at the femoral neck, total hip and distal radius. Moreover, the incidence of new vertebral fractures at 36 months showed a significant decrease of $62 \%$ in the denosumab compared to the placebo group. ${ }^{88}$

\section{Strontium ranelate}

Strontium ranelate, which has been widely used for the treatment of postmenopausal osteoporosis, has recently been approved for use in osteoporotic men. A recent open-label study randomized 152 men either to strontium ranelate ( $2 \mathrm{gr} /$ day p.o.) or alendronate (70 mg once weekly p.o.) for 12 months. ${ }^{89}$ Those patients who received strontium ranelate showed a $22 \%$ and $23 \%$ greater increase in lumbar spine and hip BMD, respectively, compared with patients treated with alendronate, and better relief of low back pain. ${ }^{89}$ Another multicenter, double-blind study randomized 261 men either to $2 \mathrm{gr}$ of strontium ranelate p.o. per day or placebo. After one year of treatment, lumbar spine BMD was statistically significantly greater in the strontium ranelate group compared to the placebo group (5.3\% versus $2.9 \%$, respectively). ${ }^{90}$ It was finally concluded that the overall effect of the drug on male lumbar spine BMD was similar to its effect on postmenopausal women, assuming a similar antifracture efficacy with the use of strontium ranelate in osteoporotic men.

\section{Testosterone}

Hormone replacement therapy in adult men with acquired hypogonadism, apart from its other benefits, prevents bone loss and increases trabecular bone density. ${ }^{91}$ Men with normal values of total testosterone do not acquire increased BMD when hormone therapy is administered. Most of the studies in the literature have several limitations such as short follow-up and a small number of participants. One of the largest studies available randomized 108 men, over 65 years of age, with total testosterone levels below normal values, to use a testosterone or a placebo patch daily for 36 months. ${ }^{92}$ Although bone mineral density in the lumbar spine increased in the testosterone group, similar findings were observed in the placebo group. Thus, no superiority of hormone replacement therapy in increasing BMD was noted. The treatment applied had very little effect on patients with baseline testosterone levels of $400 \mathrm{ng} / \mathrm{dl}$, while it was clearly more beneficial to those who started treatment with levels of around $200 \mathrm{ng} / \mathrm{dl}$. In contrast, a more recent study of 70 men, over 65 , with total testosterone levels below $12.1 \mathrm{nmol} / 1$, revealed that intramuscular administration of $200 \mathrm{mg}$ of testosterone every two weeks for 36 months caused a statistically significant increase in both hip and lumbar spine BMD compared with placebo. ${ }^{93}$ Although hormone replacement therapy presented beneficial effects on bone density in men with close to normal total testosterone values, there are no data about its anti-fracture efficacy and the long-term safety of its administration. Thus, hormone replacement therapy is considered as a second-line treatment for male osteoporosis, with its main use limited to men with low testosterone levels and clinical hypogonadism.

\section{WHO NEEDS TO BE TREATED?}

Various guidelines and proposals about who should receive anti-osteoporotic treatment have been pub- 
lished. Most of them take into account the history of previous fracture, age, other medications, DXA $\mathrm{T}$-score and fracture risk (mainly calculated with the FRAX tool). ${ }^{94-97}$ The guidelines of the Greek National Medicines Agency regarding the pharmacologic treatment of osteoporosis emphasize that candidates for treatment are men over 50 who have:

- suffered a vertebral fracture and/or hip fracture

- more than one low energy fractures in other parts of the body (e.g. distal radius)

- DXA T-score $\leq-2.5$ at the femoral neck, total hip or lumbar spine

- low bone mass (T-score between -1 and -2.5) and risk of hip fracture $\geq 3 \%$ or risk of any other major osteoporotic fracture $\geq 20 \%$ over the next decade (as calculated by the FRAX tool)

- low bone mass (T-score between -1 and -2.5) and risk of a major osteoporotic fractures between $10 \%$ and $20 \%$ over the next decade (as measured with the FRAX tool) and at least one of the following factors:

- Wrist fracture at an age $\geq 65$ years

- Lumbar BMD significantly reduced compared to hip BMD

- Significant reduction of BMD in successive measurements with an interval of more than one year (rapid bone loss)

- Anti-androgen treatment for prostate cancer

- Long-term and/or repeated systemic glucocorticoid therapy at doses lower than those of prolonged systemic treatment with glucocorticoids

- More than two falls in the last year due to gait disorders, balance and visual disturbances, etc.

\section{CONCLUSIONS}

Osteoporosis and fragility fractures in men comprise a major public health issue due to the severity of their consequences and the economic burden they pose. Health providers should be aware of the limited symptoms and signs of the disease as well as of its possible underlying causes in order to decide on treatment promptly. A fragility fracture is often the first manifestation of the disease and also an alert for further investigation, as a second fracture often follows. Diagnosis is facilitated by a variety of exams, but the decision for treatment is, in many cases, based on the medical practitioner's estimation of fracture risk. Prevention and treatment follow the same principles as in osteoporosis in women, although there are fewer medication alternatives available. Identification of the aetiology of primary male osteoporosis will provide more diagnostic and treatment options.

\section{CONFLICT OF INTEREST}

The authors declare no conflict of interest.

\section{REFERENCES}

1. Johnell O, Kanis JA, 2006 An estimate of the worldwide prevalence and disability associated with osteoporotic fractures. Osteoporos Int 17: 1726-1733.

2. Haentjens P, Magaziner J, Colon-Emeric CS, et al, 2010 Meta-analysis: excess mortality after hip fracture among older women and men. Ann Intern Med 152: 380-390.

3. Feldstein AC, Nichols G, Orwoll E, et al, 2005 The near absence of osteoporosis treatment in older men with fractures. Osteoporos Int 16: 953-962.

4. Papaioannou A, Kennedy CC, Ioannidis G, et al, 2008 The osteoporosis care gap in men with fragility fractures: the Canadian Multicentre Osteoporosis Study. Osteoporos Int 19: 581-587.

5. WHO, 1994 Assessment of fracture risk and its application to screening for postmenopausal osteoporosis. Technical Report Series. WHO, Geneva.

6. Looker AC, Orwoll ES, Johnston CC Jr., et al, 1997 Prevalence of low femoral bone density in older U.S. adults from NHANES III. J Bone Miner Res 12: 17611768 .

7. Baim S, Binkley N, Bilezikian JP, et al, 2008 Official Positions of the International Society for Clinical Densitometry and executive summary of the 2007 ISCD Position Development Conference. J Clin Densitom 11: 75-91.

8. Kaufman JM, Goemaere S, 2008 Osteoporosis in men. Best Pract Res Clin Endocrinol Metab 22: 787-812.

9. NOF, 2002 America's Bone Health: The State of Osteoporosis and Low Bone Mass in Our Nation. Washington, DC: National Osteoporosis Foundation.

10. Johnell O, Kanis J, 2005 Epidemiology of osteoporotic fractures. Osteoporos Int 16: Suppl 2: 3-7.

11. Abrahamsen B, van Staa T, Ariely R, Olson M, Cooper C, 2009 Excess mortality following hip fracture: a systematic epidemiological review. Osteoporos Int 20: 1633-1650. 
12. Endo Y, Aharonoff GB, Zuckerman JD, Egol KA, Koval KJ, 2005 Gender differences in patients with hip fracture: a greater risk of morbidity and mortality in men. J Orthop Trauma 19: 29-35.

13. Holt G, Smith R, Duncan K, Hutchison JD, Gregori A, 2008 Gender differences in epidemiology and outcome after hip fracture: evidence from the Scottish Hip Fracture Audit. J Bone Joint Surg Br 90: 480-483.

14. Tosteson AN, Gottlieb DJ, Radley DC, Fisher ES, Melton LJ, 3rd, 2007 Excess mortality following hip fracture: the role of underlying health status. Osteoporos Int 18: 1463-1472.

15. Pande I, Scott DL, O’Neill TW, Pritchard C, Woolf AD, Davis MJ, 2006 Quality of life, morbidity, and mortality after low trauma hip fracture in men. Ann Rheum Dis 65: 87-92.

16. Kanis JA, Johnell O, 2005 Requirements for DXA for the management of osteoporosis in Europe. Osteoporos Int 16: 229-238.

17. Gullberg B, Johnell O, Kanis JA, 1997 World-wide projections for hip fracture. Osteoporos Int 7: 407-413.

18. Abrahamsen B, Vestergaard P, 2010 Declining incidence of hip fractures and the extent of use of anti-osteoporotic therapy in Denmark 1997-2006. Osteoporos Int 21: 373-380.

19. Melton LJ, 3rd, Kearns AE, Atkinson EJ, et al, 2009 Secular trends in hip fracture incidence and recurrence. Osteoporos Int 20: 687-694.

20. Fisher AA, O’Brien ED, Davis MW, 2009 Trends in hip fracture epidemiology in Australia: possible impact of bisphosphonates and hormone replacement therapy. Bone 45: 246-253.

21. Leslie WD, O’Donnell S, Jean S, et al, 2009 Trends in hip fracture rates in Canada. JAMA 302: 883-889.

22. Goettsch WG, de Jong RB, Kramarz P, Herings RM, 2007 Developments of the incidence of osteoporosis in The Netherlands: a PHARMO study. Pharmacoepidemiol Drug Saf 16: 166-172.

23. Icks A, Haastert B, Wildner M, Becker C, Meyer G, 2008 Trend of hip fracture incidence in Germany 1995-2004: a population-based study. Osteoporos Int 19: 1139-1145.

24. Mann E, Icks A, Haastert B, Meyer G, 2008 Hip fracture incidence in the elderly in Austria: an epidemiological study covering the years 1994 to 2006 . BMC Geriatr 8: 35 .

25. Piscitelli P, Gimigliano F, Gatto S, et al, 2010 Hip fractures in Italy: 2000-2005 extension study. Osteoporos Int 21: 1323-1330.

26. Boonen S, Kaufman JM, Goemaere S, Bouillon R, Vanderschueren D, 2007 The diagnosis and treatment of male osteoporosis: Defining, assessing, and preventing skeletal fragility in men. Eur J Intern Med 18: 6-17.

27. Trovas GP, Lyritis GP, 1997 Aetiology in male osteoporosis. J Bone Miner Res 12: Suppl: 370.

28. Khosla S, Amin S, Orwoll E, 2008 Osteoporosis in men. Endocr Rev 29: 441-464
29. Riggs BL, Melton LJ 3rd, Robb RA, et al, 2004 Population-based study of age and sex differences in bone volumetric density, size, geometry, and structure at different skeletal sites. J Bone Miner Res 19: 1945-1954.

30. Khosla S, Riggs BL, Atkinson EJ, et al, 2006 Effects of sex and age on bone microstructure at the ultradistal radius: a population-based noninvasive in vivo assessment. J Bone Miner Res 21: 124-131.

31. Riggs BL, Melton LJ, Robb RA, et al, 2008 A population-based assessment of rates of bone loss at multiple skeletal sites: evidence for substantial trabecular bone loss in young adult women and men. J Bone Miner Res 23: 205-214.

32. Lauretani F, Bandinelli S, Griswold ME, et al, 2008 Longitudinal changes in BMD and bone geometry in a population-based study. J Bone Miner Res 23: 400-408.

33. Marshall LM, Lang TF, Lambert LC, Zmuda JM, Ensrud KE, Orwoll ES, 2006 Dimensions and volumetric BMD of the proximal femur and their relation to age among older U.S. men. J Bone Miner Res 21: 1197-1206.

34. Silva MJ, Gibson LJ, 1997 Modeling the mechanical behavior of vertebral trabecular bone: effects of agerelated changes in microstructure. Bone 21: 191-199.

35. Aaron JE, Makins NB, Sagreiya K, 1987 The microanatomy of trabecular bone loss in normal aging men and women. Clin Orthop Relat Res 215: 260-271.

36. Callewaert F, Boonen S, Vanderschueren D, 2010 Sex steroids and the male skeleton: a tale of two hormones. Trends Endocrinol Metab 21: 89-95.

37. Khosla S, Melton LJ 3rd, Robb RA, et al, 2005 Relationship of volumetric BMD and structural parameters at different skeletal sites to sex steroid levels in men. $\mathrm{J}$ Bone Miner Res 20: 730-740.

38. Orwoll E, Lambert LC, Marshall LM, et al, 2006 Testosterone and estradiol among older men. J Clin Endocrinol Metab 91: 1336-1344.

39. Gennari L, Merlotti D, Martini G, et al, 2003 Longitudinal association between sex hormone levels, bone loss, and bone turnover in elderly men. J Clin Endocrinol Metab 88: 5327-5333.

40. Mellstrom D, Vandenput L, Mallmin H, et al, 2008 Older men with low serum estradiol and high serum SHBG have an increased risk of fractures. J Bone Miner Res 23: 1552-1560.

41. Fink HA, Ewing SK, Ensrud KE, et al, 2006 Association of testosterone and estradiol deficiency with osteoporosis and rapid bone loss in older men. J Clin Endocrinol Metab 91: 3908-3915.

42. Falahati-Nini A, Riggs BL, Atkinson EJ, O'Fallon WM, Eastell R, Khosla S, 2000 Relative contributions of testosterone and estrogen in regulating bone resorption and formation in normal elderly men. J Clin Invest 106: 1553-1560.

43. Leder BZ, LeBlanc KM, Schoenfeld DA, Eastell R, Finkelstein JS, 2003 Differential effects of androgens and estrogens on bone turnover in normal men. J Clin 
Endocrinol Metab 88: 204-210.

44. Khosla S, 2008 Estrogen and bone: insights from estrogen-resistant, aromatase-deficient, and normal men. Bone 43: 414-417.

45. LeBlanc ES, Nielson CM, Marshall LM, et al, 2009 The effects of serum testosterone, estradiol, and sex hormone binding globulin levels on fracture risk in older men. J Clin Endocrinol Metab 94: 3337-3346.

46. Khosla S, 2010 Update in male osteoporosis. J Clin Endocrinol Metab 95: 3-10.

47. Amin S, Zhang Y, Felson DT, et al, 2006 Estradiol, testosterone, and the risk for hip fractures in elderly men from the Framingham Study. Am J Med 119: 426-433.

48. Haney EM, Bliziotes MM, 2008 Male osteoporosis: new insights in an understudied disease. Curr Opin Rheumatol 20: 423-428.

49. Khosla S, 2009 Testosterone: more is not always better. J Clin Endocrinol Metab 94: 4665-4667.

50. Van Pottelbergh I, Goemaere S, Kaufman JM, 2003 Bioavailable estradiol and an aromatase gene polymorphism are determinants of bone mineral density changes in men over 70 years of age. J Clin Endocrinol Metab 88: 3075-3081.

51. Giustina A, Mazziotti G, Canalis E, 2008 Growth hormone, insulin-like growth factors, and the skeleton. Endocr Rev 29: 535-559.

52. Khosla S, Melton LJ 3rd, Achenbach SJ, Oberg AL, Riggs BL, 2006 Hormonal and biochemical determinants of trabecular microstructure at the ultradistal radius in women and men. J Clin Endocrinol Metab 91: 885-891.

53. Veldhuis JD, Bowers CY, 2003 Human GH pulsatility: an ensemble property regulated by age and gender. $\mathrm{J}$ Endocrinol Invest 26: 799-813.

54. Amin S, Riggs BL, Melton LJ 3rd, Achenbach SJ, Atkinson EJ, Khosla S, 2007 High serum IGFBP-2 is predictive of increased bone turnover in aging men and women. J Bone Miner Res 22: 799-807.

55. Felson DT, Zhang Y, Hannan MT, Anderson JJ, 1993 Effects of weight and body mass index on bone mineral density in men and women: the Framingham study. J Bone Miner Res 8: 567-573.

56. De Laet C, Kanis JA, Oden A, et al, 2005 Body mass index as a predictor of fracture risk: a meta-analysis. Osteoporos Int 16: 1330-1338.

57. Cornish J, Callon KE, Bava U, et al, 2002 Leptin directly regulates bone cell function in vitro and reduces bone fragility in vivo. J Endocrinol 175: 405-415.

58. Gordeladze JO, Drevon CA, Syversen U, Reseland JE, 2002 Leptin stimulates human osteoblastic cell proliferation, de novo collagen synthesis, and mineralization: Impact on differentiation markers, apoptosis, and osteoclastic signaling. J Cell Biochem 85: 825-836.

59. Holloway WR, Collier FM, Aitken CJ, et al, 2002 Leptin inhibits osteoclast generation. J Bone Miner Res 17: 200-209.

60. Elefteriou F, Ahn JD, Takeda S, et al., 2005 Leptin regulation of bone resorption by the sympathetic nervous system and CART. Nature 434: 514-520.

61. Takeda S, Elefteriou F, Levasseur R, et al, 2002 Leptin regulates bone formation via the sympathetic nervous system. Cell 111: 305-317.

62. Reid IR, 2008 Relationships between fat and bone. Osteoporos Int 19: 595-606.

63. Martin A, David V, Malaval L, Lafage-Proust MH, Vico L, Thomas T, 2007 Opposite effects of leptin on bone metabolism: a dose-dependent balance related to energy intake and insulin-like growth factor-I pathway. Endocrinology 148: 3419-3425.

64. Luo XH, Guo LJ, Xie H, et al, 2006 Adiponectin stimulates RANKL and inhibits OPG expression in human osteoblasts through the MAPK signaling pathway. J Bone Miner Res 21: 1648-1656.

65. Shinoda Y, Yamaguchi M, Ogata N, et al, 2006 Regulation of bone formation by adiponectin through autocrine/ paracrine and endocrine pathways. J Cell Biochem 99: 196-208.

66. Basurto L, Galvan R, Cordova N, et al, 2009 Adiponectin is associated with low bone mineral density in elderly men. Eur J Endocrinol 160: 289-293.

67. Abrahamsen B, Rohold A, Henriksen JE, Beck-Nielsen H, 2000 Correlations between insulin sensitivity and bone mineral density in non-diabetic men. Diabet Med 17: 124-129.

68. Liu H, Paige NM, Goldzweig CL, et al, 2008 Screening for osteoporosis in men: a systematic review for an American College of Physicians guideline. Ann Intern Med 148: 685-701.

69. Meier C, Nguyen TV, Center JR, Seibel MJ, Eisman JA, 2005 Bone resorption and osteoporotic fractures in elderly men: the dubbo osteoporosis epidemiology study. J Bone Miner Res 20: 579-587.

70. Szulc P, Kaufman JM, Delmas PD, 2007 Biochemical assessment of bone turnover and bone fragility in men. Osteoporos Int 18: 1451-1461.

71. Cannell JJ, Hollis BW, Zasloff M, Heaney RP, 2008 Diagnosis and treatment of vitamin D deficiency. Expert Opin Pharmacother 9: 107-118.

72. NIH, 1994 NIH Consensus statement, Volume 12, Number 4 (ed.). Bethesda, MD: National Institutes of Health.

73. Tang BM, Eslick GD, Nowson C, Smith C, Bensoussan A, 2007 Use of calcium or calcium in combination with vitamin D supplementation to prevent fractures and bone loss in people aged 50 years and older: a meta-analysis. Lancet 370: 657-666.

74. Boonen S, Lips P, Bouillon R, Bischoff-Ferrari HA, Vanderschueren D, Haentjens P, 2007 Need for additional calcium to reduce the risk of hip fracture with vitamin d supplementation: evidence from a comparative metaanalysis of randomized controlled trials. J Clin Endocrinol Metab 92: 1415-1423.

75. Boonen S, Vanderschueren D, Haentjens P, Lips P, 2006 
Calcium and vitamin D in the prevention and treatment of osteoporosis - a clinical update. J Intern Med 259: 539-552.

76. Orwoll E, Ettinger M, Weiss S, et al, 2000 Alendronate for the treatment of osteoporosis in men. N Engl J Med 343: 604-610.

77. Miller PD, Schnitzer T, Emkey R, et al, 2004 Weekly oral alendronic Acid in male osteoporosis. Clin Drug Investig 24: 333-341.

78. Ringe JD, Dorst A, Faber H, Ibach K, 2004 Alendronate treatment of established primary osteoporosis in men: 3 -year results of a prospective, comparative, two-arm study. Rheumatol Int 24: 110-113.

79. Iwamoto J, Takeda T, Sato Y, 2007 Effects of antifracture drugs in postmenopausal, male and glucocorticoidinduced osteoporosis--usefulness of alendronate and risedronate. Expert Opin Pharmacother 8: 2743-2756.

80. Boonen S, Orwoll ES, Wenderoth D, Stoner KJ, Eusebio R, Delmas PD, 2009 Once-weekly risedronate in men with osteoporosis: results of a 2-year, placebo-controlled, double-blind, multicenter study. J Bone Miner Res 24: 719-725.

81. Ringe JD, Farahmand P, Faber H, Dorst A, 2009 Sustained efficacy of risedronate in men with primary and secondary osteoporosis: results of a 2-year study. Rheumatol Int 29: 311-315.

82. Sato Y, Iwamoto J, Kanoko T, Satoh K, 2005 Risedronate sodium therapy for prevention of hip fracture in men 65 years or older after stroke. Arch Intern Med 165: 1743-1748.

83. Lyles KW, Colon-Emeric CS, Magaziner JS, et al, 2007 Zoledronic acid and clinical fractures and mortality after hip fracture. N Engl J Med 357: 1799-1809.

84. Orwoll ES, Miller PD, Adachi JD, et al, 2010 Efficacy and safety of a once-yearly i.v. Infusion of zoledronic acid $5 \mathrm{mg}$ versus a once-weekly 70 -mg oral alendronate in the treatment of male osteoporosis: a randomized, multicenter, double-blind, active-controlled study. J Bone Miner Res 25: 2239-2250.

85. Boonen S, Reginster JY, Kaufman JM, et al, 2012 Fracture risk and zoledronic acid therapy in men with osteoporosis. N Engl J Med 367: 1714-1723.

86. Orwoll ES, Scheele WH, Paul S, et al, 2003 The effect of teriparatide [human parathyroid hormone (1-34)] therapy on bone density in men with osteoporosis. J
Bone Miner Res 18: 9-17.

87. Kaufman JM, Orwoll E, Goemaere S, et al, 2005 Teriparatide effects on vertebral fractures and bone mineral density in men with osteoporosis: treatment and discontinuation of therapy. Osteoporos Int 16: 510-516.

88. Smith MR, Egerdie B, Hernandez Toriz N, et al, 2009 Denosumab in men receiving androgen-deprivation therapy for prostate cancer. N Engl J Med 361: 745-755.

89. Ringe JD, Dorst A, Farahmand P, 2010 Efficacy of strontium ranelate on bone mineral density in men with osteoporosis. Arzneimittelforschung 60: 267-272.

90. Kaufman JM, Ringe J, Felsenberg D, et al, 2011 Efficacy and safety of strontium renalate in the treatment of male osteoporosis. Osteoporos Int 22: Suppl 1: 114-115.

91. Katznelson L, Finkelstein JS, Schoenfeld DA, Rosenthal DI, Anderson EJ, Klibanski A, 1996 Increase in bone density and lean body mass during testosterone administration in men with acquired hypogonadism. J Clin Endocrinol Metab 81: 4358-4365.

92. Snyder PJ, Peachey H, Hannoush P, et al, 1999 Effect of testosterone treatment on bone mineral density in men over 65 years of age. J Clin Endocrinol Metab 84: 1966-1972.

93. Amory JK, Watts NB, Easley KA, et al, 2004 Exogenous testosterone or testosterone with finasteride increases bone mineral density in older men with low serum testosterone. J Clin Endocrinol Metab 89: 503-510.

94. Compston J, Bowring C, Cooper A, et al, 2013 Diagnosis and management of osteoporosis in postmenopausal women and older men in the UK: National Osteoporosis Guideline Group (NOGG) update 2013. Maturitas 75: 392-396.

95. Raef H, Al-Bugami M, Balharith S, et al, 2011 Updated recommendations for the diagnosis and management of osteoporosis: a local perspective. Annals of Saudi medicine 31: 111-128.

96. Gluszko P, Lorenc RS, Karczmarewicz E, Misiorowski W, Jaworski M, 2014 Polish guidelines for the diagnosis and management of osteoporosis: a review of 2013 update. Polskie Archiwum Medycyny Wewnetrznej 124: 255-263.

97. Papaioannou A, Morin S, Cheung AM, et al, 2010 2010 Clinical practice guidelines for the diagnosis and management of osteoporosis in Canada: summary. CMAJ 182: 1864-1873. 